\title{
Clinical significance of ERG rearrangement subtype and its association with increased p53 expression in Japanese and German prostate cancer
}

\author{
J. NISHIJIMA ${ }^{1}$, T. HARA ${ }^{1}$, K. IKEMOTO ${ }^{2}$, A. OGA ${ }^{2}$, K. KOBAYASHI ${ }^{1}$, Y. KAWAI ${ }^{1}$, H. MATSUMOTO ${ }^{1}$, K. NAGAO ${ }^{1}$, K. SASAKI ${ }^{2}$, V. GKOLEIZAKIS ${ }^{3}$, \\ J. FICHTNER ${ }^{3}$, H. MATSUYAMA ${ }^{1, *}$
}

${ }^{1}$ Department of Urology, Yamaguchi University School of Medicine, 1-1-1, Minami-Kogushi, Ube, Yamaguchi 755-8505, Japan; ${ }^{2}$ Department of Pathology, Yamaguchi University School of Medicine, 1-1-1 Minami-kogushi, Ube, Yamaguchi 755-8505, Japan; ${ }^{3}$ Klinikum Niederrhein, Johanniter Krankenhaus, Steinbrinkstr. 96, 46145 Oberhausen, Germany

${ }^{*}$ Correspondence: hidde@yamaguchi-u.ac.jp

Received February 16, 2014 / Accepted July 8, 2014

\begin{abstract}
This study investigated differences in prevalence of the androgen-regulated transmembrane protease serine 2 (TMPRSS2) and ETS transcription factor family member, v-ets erythroblastosis virus E26 oncogene homolog (ERG) fusion gene (TMPRSS2-ERG fusions) in clinically localized prostate cancer Japanese and German patients. A total of 105 specimens, including 69 Japanese and 36 German patients, were collected. The status of TMPRSS2-ERG fusion was determined by fluorescence in situ hybridization, and correlations of the TMPRSS2-ERG fusion with clinicopathological characteristics and immunohistochemistry were studied. Gene fusions were identified in 20\% (14/69) of Japanese and 53\% (19/36) of German patients $(P<0.001)$. The difference in the type of gene fusion between the two ethnic groups was statistically significant $(P=0.024)$. Overexpression of ERG protein was significantly associated with gene fusion. Biochemical recurrence was significantly higher in patients with ERG overexpression than in those without, and not related to TMPRSS2-ERG fusion status. Interestingly, two types of gene fusions (deletion and increase of copy number) were significantly associated with increased 553 expression $(P=0.005)$. Association of specific gene fusions harboring higher genomic alterations with p53 expression levels suggests that p53 mutation might drive more aggressive rearrangements of TMPRSS2-ERG fusion in prostate cancer.
\end{abstract}

Key words: ERG, p53, prostate cancer, TMPRSS2-ERG fusion

Fusions between the androgen-regulated transmembrane protease serine 2 (TMPRSS2, located on 21q22.3) and the ETS transcription factor family member v-ets erythroblastosis virus E26 oncogene homolog (ERG, located on 21q22.2) are observed in a substantial portion of patients with prostate cancer $[1,2]$. These TMPRSS2-ERG fusions are present in approximately $15-80 \%$ of prostate cancers [3-6]. TMPRSS2$E R G$ fusions lead to high levels of ERG protein expression [7]. The association of the TMPRSS2-ERG fusions with prostate cancer prognosis has been evaluated in many studies, but with contradictory results. The fusions may alter the expression of the involved genes, but the clinical effect of this regulation is not fully understood [8-12].

Accumulating evidence has suggested that there are considerable ethnic variations in the incidence and clinical manifestation of prostate cancer, from the highest incidence in North American and European countries to the lowest in
Asian populations [13]. Thus, it is reasonable to hypothesize that ethnic variation in the frequency of genetic mutations, including TMPRSS2-ERG fusion, might be associated with prostate cancer risk and progression.

The aims of this study were to investigate the difference in prevalence of the TMPRSS2-ERG fusion between Japanese and German patients, and to compare the status of the TMPRSS2$E R G$ fusion with clinicopathological characteristics and patient prognosis in clinically localized prostate cancer.

\section{Patients and methods}

Patients and specimens. A total of 105 specimens were obtained from patients who were diagnosed with clinically localized prostate cancer and underwent radical prostatectomy (RP). Of the 105 total specimens, 36 were from Johanniter Krankenhaus, Germany and 69 were from 
A)

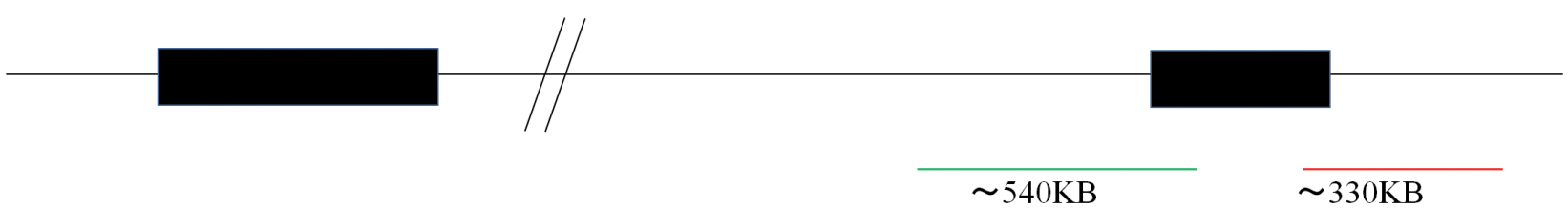

B)
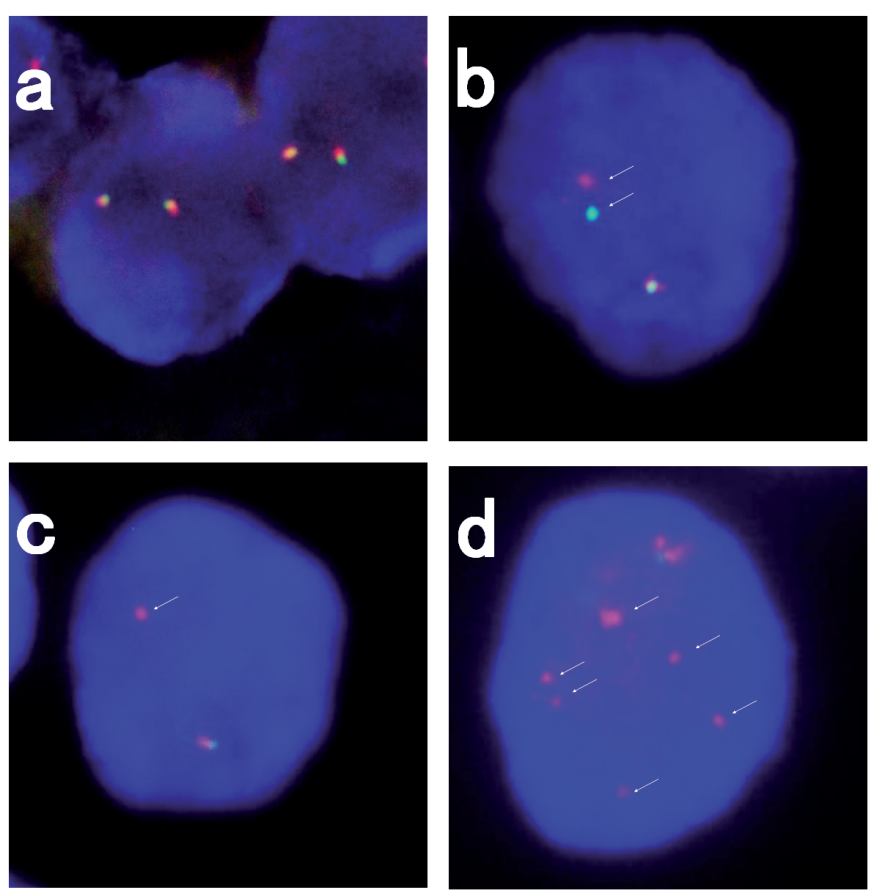

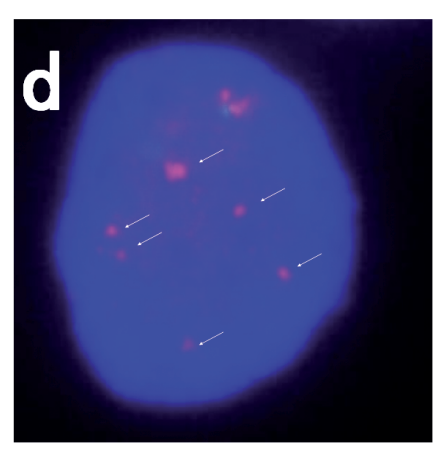

Figure 1 . (A) Schematic illustration of the design and labeling models for the $E R G$ break-apart rearrangement probe (B)Representative cases of the status of TMPRSS2-ERG fusion by FISH

(A) TMPRESS2-ERG gene fusions were detected by the FISH technique with two probes: 5'-ERG (FITC-labeled, green line) and 3'-ERG (TexRed-labeled, red line).

(B) (a) Negative gene fusion showing two signal sets with a pair of red and green signals seen in each cell. (b) Translocation was defined as a combined signal set with a pair signal and a separate signal (arrow), suggesting the gene fusion in one allele. (c) Deletion was defined as a combined signal set with a pair signal and a red signal lacking a corresponding green signal (arrow) suggesting the gene fusion in one allele with deletion of the chromosomal region hybridized to the green probe. (d) Increase of copy number was defined as a signal set and multiple red signals of the red signal (arrow) suggesting the gene fusion in one allele with amplification of the chromosomal region hybridized to the red signal probe.
Yamaguchi University Hospital, Japan. Patients who received hormonal or radiation therapy before or after RP were excluded. Clinicopathological parameters, including age, preoperative prostate-specific antigen (PSA), Gleason score, pathological $\mathrm{T}$ and $\mathrm{N}$ stage, lymphovascular invasion, and status of resection margin, were collected from patient medical records. The Gleason score was assessed in accordance with the criteria outlined at the 2005 International Society of Urological Pathology Consensus Conference [14]. Biochemical recurrence (BCR) was defined as a PSA $>0.2 \mathrm{ng} / \mathrm{mL}$, or a PSA rise in at least consecutive twice evaluations.

Tissue preparation. Slides of the prostatectomy specimens stained by hematoxylin and eosin were reviewed by two urologic pathologists (AO, KS). Slides containing the tumor were marked and paraffin blocks of the corresponding area were applied to construct the tissue microarray (TMA), as described elsewhere [15]. In brief, two representative core tumor tissue sections ( $2 \mathrm{~mm}$ in diameter) were taken from an individual paraffin block and arranged in a new TMA block.
ERG break-apart assay. We analyzed the rearrangement of the TMPRSS2-ERG fusion with break-apart fluorescence in situ hybridization (FISH) $[10,16,17]$. The break-apart probes, a FITC-labeled 5' ERG probe (BAC GSP1581G08, GSP1485E03, GSP1097C10) and a TexRed-labeled 3' ERG probe (BAC GSP0083F06, GSP1266F04) were obtained from the GSP laboratory (Kawasaki, Japan) (Fig 1A). Procedures, including hybridization, washing, and fluorescence detection, were performed according to the manufacturer's protocol, described in brief as follows. Sections of the paraffin block ( $4 \mu \mathrm{m}$ each) were deparaffinized and dehydrated. The slides were incubated with $0.05 \%$ pepsin at $37^{\circ} \mathrm{C}$ for $10 \mathrm{~min}$ and washed twice with phosphate-buffered saline (PBS), $\mathrm{pH} 7.4$, at room temperature (RT) for $5 \mathrm{~min}$. The slides were then fixed in $1 \%$ formaldehyde solution for $3 \mathrm{~min}$, washed twice in PBS at RT for 5 min, re-fixed in Carnoy's solution (60\% ethanol, $30 \%$ chloroform, and $10 \%$ glacial acetic acid) for $5 \mathrm{~min}$, dehydrated in $70 \%, 85 \%$, and $100 \%$ ethanol solution for $2 \mathrm{~min}$ each, and air dried. The probe set was applied onto the slides, 
and the slides were covered with a coverslip and sealed with rubber cement. The slides were incubated at $75^{\circ} \mathrm{C}$ for $5 \mathrm{~min}$ to denature the probe and then at $37^{\circ} \mathrm{C}$ for $72 \mathrm{~h}$ in a humidified chamber to allow hybridization. Post-hybridization washes were performed in $2 \mathrm{X}$ standard saline citrate containing $0.3 \%$ Nonidet P-40 (NP-40) for $5 \mathrm{~min}$ at RT and at $73^{\circ} \mathrm{C}$ for 2 min twice, followed by air drying and counterstaining with a DAPI-II antifade solution (Abbott Molecular, Downers Grove, IL, USA). At least 100 nuclei with FISH signals were analyzed under a BX60 fluorescence microscope (Olympus, Tokyo, Japan) with triple band-pass filter equipment (Chroma, Bellows Falls, VT, USA). In the quantification of FISH signals, overlapping cells and cells with indistinct and blurry signals were avoided, as evaluation of these cells was difficult.

To establish normal cutoffs for scoring, seven specimens of non-neoplastic prostate tissue were analyzed, and the mean and SD for TMPRSS2-ERG fusion signal ratios were calculated. A tumor was considered to have gene fusion if the percentage of cells showing a 0 or 1 ERG probe signal was greater than $3 \mathrm{SD}(1.96 \pm 7.83 \%)$ above the mean established from the normal tissue.

Signals were evaluated as: [1] negative: the two combined red and green signals (Fig 1Ba); [2] translocation: one combined signal and one separated red and green signal (Fig 1Bb); [3] deletion: one combined signal and a single copy of the

Table 1. Clinical and pathological characteristics of patients

\begin{tabular}{|c|c|c|c|c|}
\hline Parameter & & Japanese & German & P-value \\
\hline No. of patients & & 69 & 36 & \\
\hline Age (years) & & $66.7 \pm 5.6$ & $65.4 \pm 5.3$ & $0.23^{+}$ \\
\hline Preoperative PSA (ng/ml) & & $17.1 \pm 16.4$ & - & - \\
\hline \multirow[t]{3}{*}{ Gleason score } & $4-6$ & 19 & 26 & $<0.001^{\S}$ \\
\hline & 7 & 35 & 10 & \\
\hline & $8-10$ & 15 & 0 & \\
\hline \multirow[t]{2}{*}{ Tumor stage } & $\leq \mathrm{pT} 2$ & 49 & 36 & $<0.001^{*}$ \\
\hline & $\geq \mathrm{pT} 3$ & 17 & 0 & \\
\hline \multirow[t]{2}{*}{ LVI } & Positive & 29 & - & - \\
\hline & Negative & 35 & - & \\
\hline \multirow[t]{2}{*}{ SM } & Positive & 42 & - & - \\
\hline & Negative & 23 & - & \\
\hline \multirow[t]{2}{*}{ Biochemical recurrence } & Yes & 13 & 4 & $0.41^{\ddagger}$ \\
\hline & No & 53 & 32 & \\
\hline
\end{tabular}

Abbreviations: LVI, lymphovascular invasion; PSA, prostate-specific antigen; SM, surgical margin

Data are presented as mean \pm SD.

Statistical analyses were used as follows: $†$ Wilcoxon rank sum test, $\neq$ Fisher's exact test and $₫$ Chi-square test. red signal (Fig $1 \mathrm{Bc})$; and [4] increase of copy number: one combined signal and many copies of the red signal (Fig 1Bd), according to the previous report $[4,10]$. FISH interpretation was performed by two urologic pathologists (AO, KS).

Immunohistochemistry. The corresponding specimens of FISH slides from TMA were analyzed by immunohistochemistry (IHC). Antibodies against the following proteins were used: ERG (rabbit polyclonal, 1:500 dilution; Santa Cruz Biotechnology, Santa Cruz, CA, USA), PTEN (mouse monoclonal, 1:100 dilution; Dako, Carpinteria, CA, USA), NKX3.1 (rabbit polyclonal, 1:100 dilution; Abcam, Cambridge, MA, USA), Ki-67 (rabbit polyclonal, 1:500 dilution; Abcam), AR (mouse monoclonal, 1:75 dilution; Dako), and p53 (clone DO-7, mouse monoclonal, 1:50 dilution; Dako). The selection of these antibodies was based on cell-cycle-related proteins, androgen-responsible gene products, and gene products frequently reported to be closely associated with TMPRSS2-ERG fusion.

After rehydration, endogenous peroxidase was inactivated for $10 \mathrm{~min}$ in $0.3 \% \mathrm{H}_{2} \mathrm{O}_{2}$ in methanol. Slides were incubated with $10 \mathrm{mM}$ sodium citrate buffer, $\mathrm{pH}$ 6.0. Nonspecific binding sites were blocked with $1 \%$ bovine serum albumin and $0.1 \%$ Tween 20 (Sigma, Saint Louis, MO, USA) in PBS. The slides were incubated with a primary antibody in a controlled dilution overnight at $4^{\circ} \mathrm{C}$. The sections were incubated with Histofine Simple Stain Rat MAX-PO (MULTI) (Nichirei Biosciences Inc., Tokyo, Japan) for $30 \mathrm{~min}$ at RT. Immunoreactive species were detected with DAB (Nichirei Biosciences Inc.). The slides were counterstained with hematoxylin.

Samples were assigned a mean score $(0$, no staining, 1 , weak staining, 2, moderate staining, 3 , strong staining) and a staining score (H-score) was calculated by multiplying the mean intensity score and the percent of positive cells stained, with a value in the range of $0-300$. For categorical dichotomization, the $\mathrm{H}$-score of 100-150 (median score of each antibody) was used as a cut-off to categorize high and low. P53 mutation was also determined based on the $\mathrm{H}$-score described above.

Statistics. The Chi-square test or the Fisher's exact test was used to compare the results of the ERG break-apart assay in accordance with the clinicopathological variables and histological pattern. Univariate analysis of a risk factor for biochemical recurrence used the log-rank test of the Kaplan-Meier analysis and the Cox's logistic regression analysis. Multivariate analysis was based on the Cox's proportional hazard model and the forward likelihood ratio was used. Statistical tests were two sided and p-values $<0.05$ were considered to be statistically significant. To estimate correlations among expression levels of PTEN, NKX3.1, Ki-67, AR and p53, linear regression analysis was used. All statistical analyses were conducted using JMP', version 10 (SAS Institute, Cary, NC, USA).

\section{Results}

Patient characteristics. The clinicopathological variables for the Japanese and German patients are summarized in Table 1. Japanese patients had higher Gleason scores $(>7)$ 


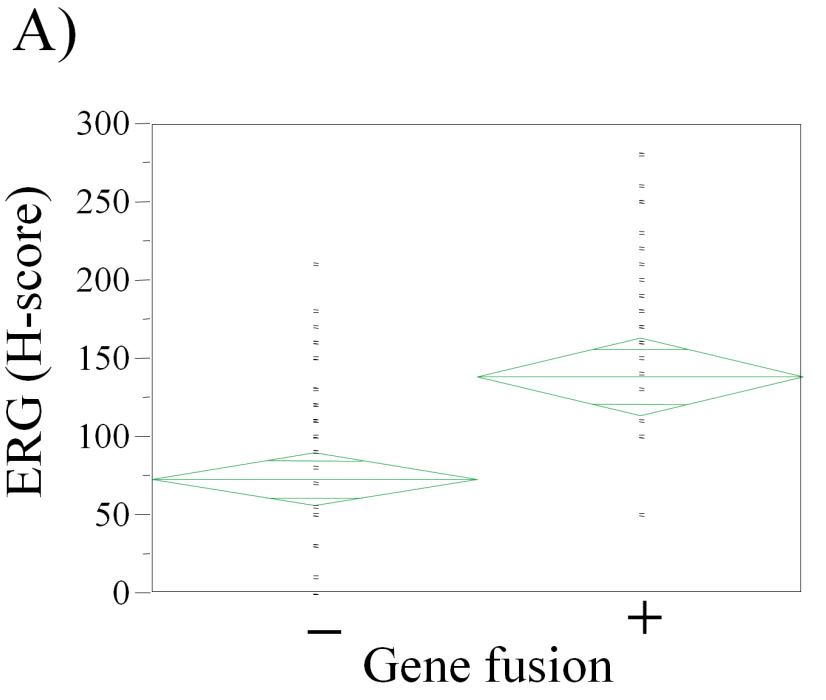

B)
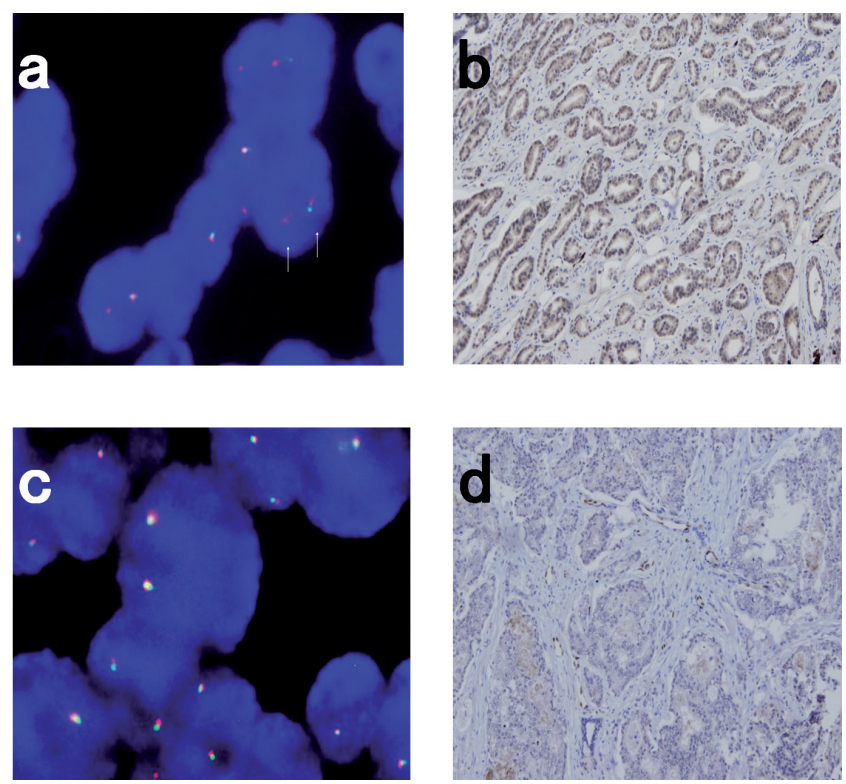

Figure 2. Relationship of gene fusion status with ERG expression and gene fusion subtype

(A) ERG expression by immunohistochemical analysis (H-score) was significantly correlated with presence of gene fusion $(P<0.001)$. (B) Status of gene fusions and ERG staining by FISH (a, c) or immunohistochemical expression of ERG (b, d). Note the blue signal that was associated with a red signal in another allele was deleted (arrow) in B-a. (a) Case with positive gene fusion (subtype: deletion); (b) positive ERG staining in the same case as in (a); (c) case with negative gene fusion; (d) negative ERG staining in the corresponding case of (c).

and a higher pathological stage compared with the German patient group $(P<0.001$ and $P<0.001$, respectively). The median follow-up durations were 53.6 years (range 6.3-106.6) in Japanese patients and 25.6 months (range 0.2-33.3) in German patients.

Table 2. Prevalence and type of TMPRSS2-ERG fusion in prostate cancer

\begin{tabular}{|c|c|c|c|}
\hline & Japanese & German & P-value \\
\hline \multicolumn{4}{|l|}{ All cases } \\
\hline Number of positive gene fusion (\%) & $14(20 \%)$ & $19(53 \%)$ & $<0.001^{\dagger}$ \\
\hline \multicolumn{4}{|l|}{ Gene fusion type } \\
\hline Translocation & $10 / 14(71 \%)$ & $6 / 19(32 \%)$ & $0.024^{\ddagger}$ \\
\hline Deletion/increase of copy number & $4 / 14(29 \%)$ & $13 / 19(68 \%)$ & \\
\hline \multicolumn{4}{|c|}{ Cases with $\leq p T 2$ and Gleason Score $\leq 6$} \\
\hline Number of positive gene fusion (\%) & $1(6 \%)$ & $13(50 \%)$ & $0.003^{\dagger}$ \\
\hline \multicolumn{4}{|l|}{ Gene fusion type } \\
\hline Translocation & $1 / 1(100 \%)$ & $5 / 13(38 \%)$ & $0.009^{*}$ \\
\hline Deletion/increase of copy number & $0 / 1(0 \%)$ & $8 / 13(62 \%)$ & \\
\hline \multicolumn{4}{|l|}{ Cases of $\leq p T 2$ and Gleason Score $>7$} \\
\hline Number of positive gene fusion (\%) & $7(22 \%)$ & $6(60 \%)$ & $0.050^{\dagger}$ \\
\hline \multicolumn{4}{|l|}{ Gene fusion type } \\
\hline Translocation & $4 / 7(57 \%)$ & $1 / 6(17 \%)$ & $0.013^{\ddagger}$ \\
\hline Deletion/increase of copy number & $3 / 7(43 \%)$ & $5 / 6(83 \%)$ & \\
\hline
\end{tabular}

${ }^{\dagger}$ Fisher's exact test and ${ }^{\ddagger} \mathrm{Chi}$-square test were used for statistical analyses.
TMPRSS2-ERG fusions in Japanese and German patients. The status of the TMPRSS2-ERG fusion in both groups is summarized in Table 2. Overall, gene fusion was identified in $31 \%(33 / 105)$ of prostate cancer cases. A significantly higher frequency of gene fusion was observed in German patients $(19 / 36,53 \%)$ than in Japanese patients $(14 / 69,20 \%)$ $(P<0.001)$. In several cases, cancer cells contained a heterogeneous combination of different types of gene fusion events, with translocation, deletion, and an increase of copy number observed. Among 14 gene fusion cases in Japanese patients, $71 \%(10 / 14)$ had translocation, $21 \%(3 / 14)$ had deletion, and $7 \%(1 / 14)$ had an increase in copy number. In German patients, $32 \%(6 / 19)$ had translocation, 68\% (13/19) had deletion, and no cases showed an increase in copy number. Only one case with an increase in copy number was detected in both groups.

Table 3. Univariate and multivariate analysis for TMPRSS2-ERG fusion in prostate cancer

\begin{tabular}{lccc}
\hline & Univarate & \multicolumn{2}{c}{ Multivariate } \\
Variables & P-value & OR(95\% CI $)$ & P-value \\
\hline Race (Japanese vs German) & $<0.001$ & $3.91(1.59-10.03)$ & 0.003 \\
pT stage ( $\leq$ pT2 vs $\geq$ pT3 $)$ & 0.22 & & \\
Gleason score $(\leq 6$ vs $\geq 7)$ & 0.082 & $0.54(0.07-2.32)$ & 0.43 \\
\hline
\end{tabular}

Logistic regression were used for statistical analyses. 
A)

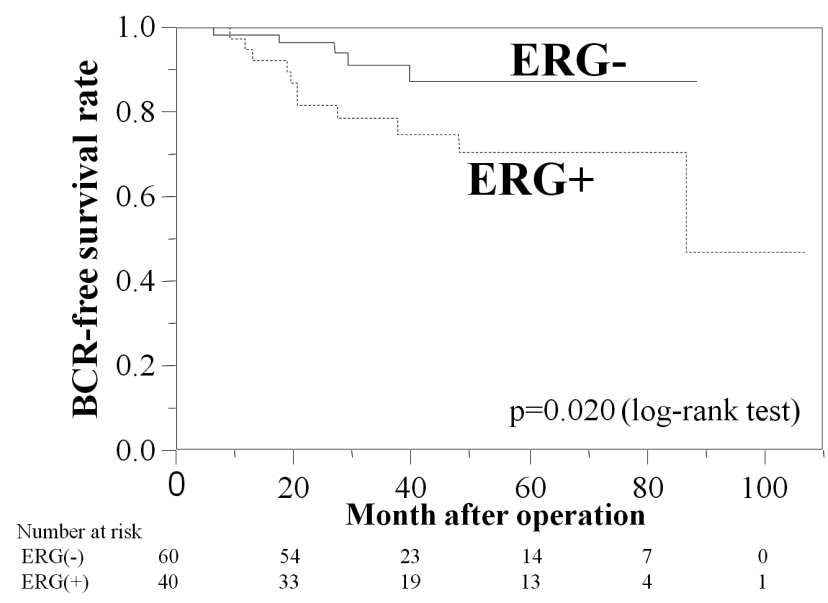

B)

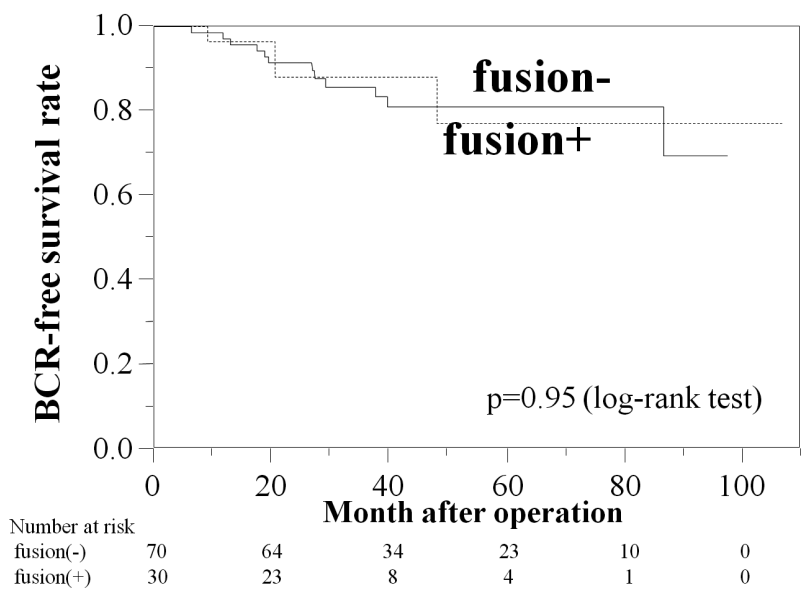

Figure 3. Biochemical recurrence-free survival rate according to presence of ERG expression (A) and gene fusion (B)

Therefore, we categorized fusion subtypes into two groups for analysis: translocation or deletion/increase in copy number. The TMPRSS2-ERG fusion subtype also differed between both ethnic groups $(P=0.024)$. Between the two groups, there was a statistically significant difference in the Gleason score and
pT stage, thus we matched these different characteristics. After adjusting for the Gleason score and $\mathrm{pT}$ stage, the German group had a significantly higher prevalence of TMPRSS2$E R G$ fusion and the Japanese group had more translocations (Table 2). We also analyzed factors including races, $\mathrm{pT}$ stage

Table 4. Relationship between type of TMPRSS2-ERG fusion and other clinicopathological parameters

\begin{tabular}{|c|c|c|c|c|c|c|}
\hline \multirow[b]{2}{*}{ Characteristic } & \multirow[b]{2}{*}{ Gene fusion $(-)$} & \multirow[b]{2}{*}{ Gene fusion $(+)$} & \multirow[b]{2}{*}{ P-value ${ }^{1}$} & \multicolumn{2}{|c|}{ Gene fusion $(+)$} & \multirow[b]{2}{*}{ P-value ${ }^{2}$} \\
\hline & & & & Translocation & $\begin{array}{l}\text { Deletion/increase } \\
\text { of copy number }\end{array}$ & \\
\hline \multicolumn{7}{|l|}{ Age (years) } \\
\hline & $66.4 \pm 5.5$ & $65.8 \pm 5.4$ & $0.81^{\dagger}$ & $65.8 \pm 5.7$ & $65.8 \pm 5.3$ & $0.96^{\dagger}$ \\
\hline \multicolumn{7}{|c|}{ Preoperative PSA (ng/mL) } \\
\hline & $18.1 \pm 17.6$ & $12.0 \pm 6.9$ & $0.62^{\dagger}$ & $11.3 \pm 7.2$ & $13.0 \pm 8.3$ & $0.57^{\dagger}$ \\
\hline \multicolumn{7}{|l|}{ Gleason score } \\
\hline $4-6$ & 31 & 14 & $0.80^{\dagger}$ & 6 & 8 & $0.61^{\dagger}$ \\
\hline 7 & 28 & 17 & & 9 & 8 & \\
\hline $8-10$ & 13 & 2 & & 1 & 1 & \\
\hline \multicolumn{7}{|l|}{ Tumor stage } \\
\hline$\leq \mathrm{pT} 2$ & 58 & 27 & $0.40^{\ddagger}$ & 11 & 16 & $0.54^{\ddagger}$ \\
\hline$\geq \mathrm{pT} 3$ & 14 & 3 & & 2 & 1 & \\
\hline \multicolumn{7}{|l|}{ LVI } \\
\hline Positive & 24 & 5 & $0.41^{*}$ & 4 & 1 & $0.20^{\ddagger}$ \\
\hline Negative & 30 & 5 & & 2 & 3 & \\
\hline \multicolumn{7}{|l|}{ SM } \\
\hline Positive & 37 & 5 & $0.58^{\ddagger}$ & 3 & 2 & $1.00^{\ddagger}$ \\
\hline Negative & 18 & 5 & & 3 & 2 & \\
\hline \multicolumn{7}{|c|}{ Biochemical recurrence } \\
\hline Yes & 13 & 4 & $0.65^{\ddagger}$ & 1 & 3 & $0.43^{\ddagger}$ \\
\hline No & 59 & 26 & & 12 & 14 & \\
\hline
\end{tabular}

Abbreviations: LVI, lymphovascular invasion; SM, surgical margin

Data are presented as mean \pm SD.

$\mathrm{P}^{1}$ shows the $\mathrm{P}$-values from the comparison of normal cases and cases with any gene fusions. $\mathrm{P}^{2}$ shows the P-values from the statistical test of any differences between cases with translocation and deletion/increase of copy number. Statistical analyses were used as follows: ${ }^{~}$ Wilcoxon rank sum test and ${ }^{\ddagger}$ Chi-square test. 
and Gleason score against TMPRESS2-ERG gene fusion using multivariate analysis (Table 3). Race was independent factor for TMPRESS2-ERG gene fusion.

Relationships between TMPRSS2-ERG fusion and clinicopathological parameters. The comparisons of the class of TMPRSS2-ERG fusion and several clinicopathological variables are summarized in Table 4. No significant association was observed between clinicopathological parameters and status of TMPRSS2-ERG fusion or fusion subtype.

Correlation of TMPRSS2-ERG gene fusion with ERG expression. Overexpression of ERG protein was significantly associated with gene fusion $(P<0.001)($ Fig $2 \mathrm{~A})$, while no fusion-negative tumors showed ERG overexpression (Fig 2A, B). No association was found between ERG expression and the subtype of gene fusion (data not shown).

Patient prognosis according to TMPRSS2-ERG fusion status and ERG expression level. BCR was observed in 17 patients (16.2\%) at a median of 20.5 months (range: 6.2-86.5). No patient died of prostate cancer. Cases with ERG overexpression had a significantly shorter time to progression than those without overexpression (Fig 3A), while TMPRSS2-ERG fusion was not related to BCR in our series (Fig 3B). Among cases with gene fusion, the incidence of BCR was higher in cases with a deletion/increase in copy number than in translocation cases, although the difference was not statistically significant (Fig 4).

Correlations with type of TMPRSS2-ERG fusion and p53 overexpression. We next examined p53 overexpression by immunohistochemistry to elucidate the possible relationship between p53 status and gene fusion. Cases with gene fusion were significantly associated with increased $\mathrm{p} 53$ expression $(P$ $=0.011)$ (Table 5). In regard to the type of gene fusion, cases with a deletion or increase in copy number had marginal association with p53 overexpression $(P=0.054$, Table 5$)$.

To examine the relationship between TMPRSS2-ERG fusion with proteins known to play important roles in prostate cancer, we next examined the expression levels of PTEN, NKX3.1, Ki-67, and AR (Table 6). Results showed that the expression levels of these four proteins were not associated with TMPRSS2-ERG fusion. However, NKX3.1 expression was significantly correlated with AR and Ki-67 expression $(P$ $<0.001$ and $P<0.001$, respectively) as well as p53 expression $(P=0.003)$. The expression level of PTEN was significantly

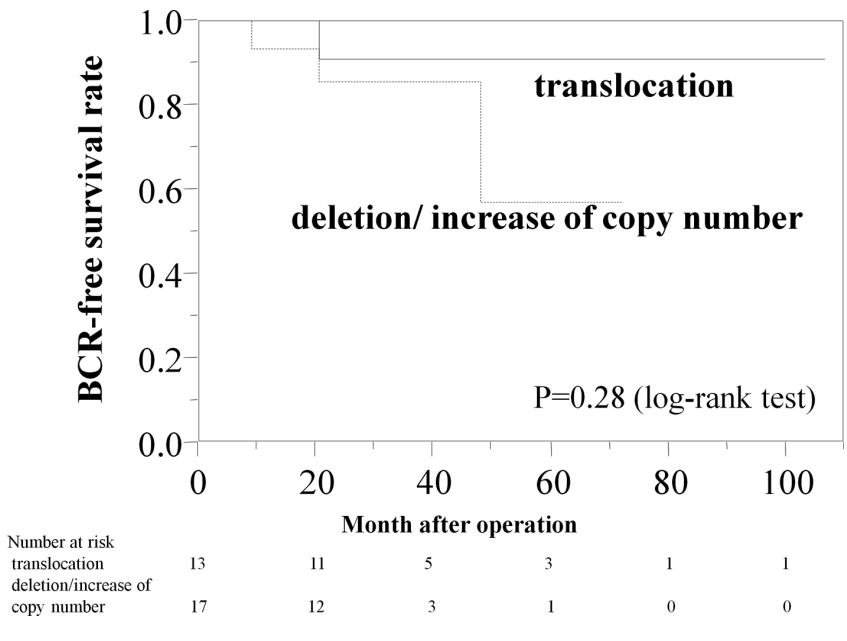

Figure 4. Biochemical recurrence-free survival rate according to gene fusion types

Table 5. Relationship between p53 mutations and type of TMPRSS2-ERG fusions

\begin{tabular}{lccc}
\hline & \multicolumn{2}{c}{$\mathrm{p} 53$ mutations } & \\
\cline { 2 - 3 } & Negative & Positive & P-value \\
\hline TMPRESS2-ERG fusions & & & \\
$\quad$ Gene fusion (+) & 13 & 20 & $0.011^{\dagger}$ \\
$\quad(-)$ & 48 & 24 & \\
Gene fusion type & & & \\
$\quad$ Translocation & 9 & 7 & $0.054^{\ddagger}$ \\
$\quad$ Deletion/increase of copy number & 4 & 13 & \\
\hline
\end{tabular}

associated with ERG expression $(P=0.002)$. AR expression was also correlated with p53 expression $(P=0.003)$.

\section{Discussion}

The frequency of incidence of the TMPRSS2-ERG fusion in prostate cancer was significantly different between Japanese and German patients ( $20 \%$ vs. $53 \%$, respectively). This result is in accordance with previous studies in Caucasian cohorts,

Table 6. Correlation between immunohistochmeical expression in prostate cancer

\begin{tabular}{lccccc}
\hline & NKX3.1 & PTEN & Ki-67 & AR & p53 \\
\hline ERG & $0.13(P=0.17)$ & $0.31(P=0.002)$ & $0.18(P=0.070)$ & $0.17(P=0.087)$ & $0.03(P=0.73)$ \\
NKX3.1 & - & $0.11(P=0.27)$ & $0.37(P<0.001)$ & $0.43(P<0.001)$ & $0.28(P=0.003)$ \\
PTEN & - & $0.07(P=0.48)$ & $0.17(P=0.080)$ & $0.14(P=0.17)$ \\
Ki-67 & & - & $0.12(P=0.21)$ & $0.09(P=0.31)$ \\
AR & & & - & $0.26(P=0.003)$ \\
p53 & & & & - \\
\hline
\end{tabular}

Linear regression analysis were used for statistical analysis. Correlation coefficient (r) and P-value were shown in the Table. 
which reported frequencies of $46-80 \%$ [3-6], and in Asian cohorts, which reported frequencies of $16-28 \%[4,9,18]$. Several studies have described the different incidence of the TMPRSS2-ERG fusion in Caucasians and non-Caucasians. Magi-Galluzzi et al. reported a significant difference in the prevalence of TMPRSS2-ERG in Caucasian, African-American, and Japanese prostate cancer patients [4].

The genes for TMPRSS2 and ERG are located approximately $3 \mathrm{Mb}$ apart in the same orientation on chromosome 21q22.2. The rearrangement between the two genes occurs via intra-chromosomal deletion or translocation of the intervening region to another chromosome $[19,20]$. The gene fusion subtypes (translocations, deletions, and increase in copy number) were significantly different among ethnic groups. Magi-Galluzzi et al. reported that translocation was the predominant subtype in Caucasians and Japanese patients (62\% and $71 \%$, respectively), while deletion was dominant in African-American patients (80\%) [4]. The higher frequency of gene fusion deletion events in African-Americans may be one of the explanations for the worse prognosis of prostate cancer in African-Americans compared with other ethnic groups. These data partially support our result showing that translocation was dominant in the Japanese patients $(71 \%)$, whereas deletion was dominant in the German patients. The discrepancy may be attributable to the different patient characteristics. Lower incidence and different subtype of TMPRSS2-ERG fusions may imply different pathways of prostate carcinogenesis between Caucasians and non-Caucasians.

The deletion and increase in copy number subtypes may confer more aggressive biological behavior to the TMPRSS2$E R G$ fusion $[10,22]$. These reports may support our data that the incidence of BCR had a higher tendency of deletion/ increase in copy number than translocation. Whether the TMPRSS2-ERG fusion affects patient prognosis remains controversial $[3,9,12,23]$. Meticulous observation of gene fusion subtype seems to be important for the prediction of prostate cancer with gene fusion. Presumably, gene fusion is one of the genetic steps in the oncogenesis of prostate cancer, particularly the dominant form in Caucasians.

Although ERG overexpression is a rare event in nonneoplastic prostate tissue, most prostate cancer patients with TMPRSS2-ERG fusion have ERG overexpression $[8,16,24$, 25]. The incidence of ERG overexpression and gene fusion was $42 \%$ and $31 \%$, respectively. The concordance rate between two methods was $66.7 \%$. As regards race, the rates in Japanese and German were $78.6 \%$ and $57.9 \%$, respectively $(\mathrm{p}=0.273)$. The discrepancy of IHC and FISH analysis results may be explained by several possibilities. Heterogeneity of genomic fusion has been previously reported in prostate cancer $[11,17,26]$. The TMPRSS2-ERG fusion might not be the only factor involved in ERG overexpression. Consistent with our findings, Spencer et al. suggested that TMPRSS2-ERG fusion itself does not increase the proliferation and progression of prostate cancer cells [7]. Alternatively, the discrepancy may be attributed to the difference in detection power between the different meth- odologies. A previous study clearly demonstrated that ERG is a key player of prostate cancer migration and invasion [27]. Minner et al. suggested that intrafocal heterogeneity challenges the concept of TMPRSS2-ERG fusion always representing an early step in prostate cancer development [26]. Taken together with the previous reports and our data, ERG overexpression seems to be critical for the estimation of aggressive behavior of prostate cancer and may become an important prognostic marker reflecting TMPRSS2-ERG fusion.

To explore the influence by which TMPRSS-ERG fusion might affect the development and progression of prostate tumorigenesis, we examined expression levels of several proteins that are known to be important for prostate carcinogenesis. Previous studies discussed that the influence of ERG rearrangements cooperating with genetic loss or alteration mutation of PTEN and p53. [22, 27-29]. NKX3.1 expression level was positively correlated with AR expression level, which was consistent with previous studies [30,31]. We found that the level of PTEN expression was positively associated with ERG expression. Prostate cancers with PTEN deletion are well known to have more aggressive behavior [28]. On the other hand, ERG rearrangements have not found an increase in frequency in relation to disease stage [32]. Therefore, ERG rearrangements seem to occur prior PTEN loss. Probably, PTEN loss and ERG rearrangements are independent events each other.

In this study, immunohistochemical detection of p53 expression was used to detect p53 mutations. The p53 antibody (clone DO-7) recognizes an epitope located within amino acids 35-45 of the N-terminus of both wild type and mutant types of p53. Wild-type p53 protein has a very short half-life, whereas mutated p53 is stable and accumulated at high concentration in the nuclei of cells. As consequence, immunohistochemical staining with the specific antibody can be used to detect mutant $\mathrm{p} 53$ proteins. Our previous study demonstrated that the concordance rate between immunohistochemistry and p53 point mutation was $80 \%$ [33]. P53 mutations have been reported in 3-20\% of prostate cancers and are often correlated with BCR and grade of the tumor with an aggressive clinical course [22, 34-36]. We could not find the relationship of Gleason score with expression level of p53, which might result from the different characteristics of our specimen which were collected from localized prostate cancers. The strong correlation of p53 overexpression with alteration of $p 53$ gene detected by polymerase chain reaction-single strand conformation polymorphism [37]. We observed that overexpression of $\mathrm{p} 53$ protein was associated with TMPRSS2-ERG fusion. Moreover, p53 overexpression were found more frequently in the deletion and increase in copy number cases than in translocation TMPRSS2-ERG fusion cases. A prolonged exposure of androgen to non-malignant prostate epithelial cells induces the TMPRSS2-ERG fusion transcript [38]. Inactivation of DNA damage checkpoint proteins, such as ataxia telangiectasia mutated (ATM) and ataxia telangiectasia and Rad3 related (ATR) protein, is a crucial step in promoting androgen-induced 
genomic instability. Cdc25A and p53 are major downstream effectors of the ATM/ATR DNA damage checkpoints. Chiu et al. demonstrated that androgen regulates the protein level of Cdc25A, but not p53, through ATM in LNCaP cells. Although androgen treatment did not alter the protein level of p53 in their experiments, p53 mutations may play an important role in the escape from the DNA damage checkpoint in prostate cancer cells [39]. Moreover, p53 overexpression represses androgen-induced transactivation of NKX3.1 by inhibiting the promoter of the AR gene and blocking AR DNA binding activity [40]. Because p53 negatively regulated androgen-induced events, p53 mutations might enhance androgen-related phenomenon including genomic instability. Indeed, we observed that expression of NKX3.1, which was upregulated by AR [31], was associated with p53 overexpression in this study. Hence, our results might indicate that $\mathrm{p} 53$ mutations might drive more aggressive arrangements of TMPRSS2-ERG fusion in prostate cancer. In contrast, Yang Zonga et al. reported to determine whether loss of p53 can collaborate with ERG overexpression during the development of PCa, prostate cells from adult p53-null mice were transduced with either ERG or control lentivirus and implanted in the prostate regeneration assay. They found no evidence to support cooperation between loss of $\mathrm{p} 53$ and increased expression of ERG, suggesting that two oncogenic influences do not always collaborate to advance the disease [41]. Carcinogenesis involves multiple genetic alterations and further accumulation of genetic alteration occurs during tumor progression. Our cohorts contain different phases of tumor progression. Therefore we believe our logic that p53 mutations drive more aggressive arrangements of TMPRSS2-ERG fusion in prostate cancer is suitable. Further studies are needed to determine whether p53 mutations may affect the occurrence of TMPRSS2-ERG fusion.

The present study has some limitations. First, we used a FISH break-apart assay, so called two-color FISH assay for detection of TMPRESS2-ERG gene fusion. Since the specific 5'-partner is not identified by the break-apart assay, the frequency of TMPRESS2-ERG fusion might be overestimated comparing with three-color FISH analysis. Second, our cohorts limited the cases with radical prostatectomy. So we could not estimate more aggressive prostate cancer in this study.

In conclusion, our study showed that the prevalence and type of TMPRSS2-ERG fusions are significantly different in Japanese and German prostate cancer cases. ERG expression, but not the presence of the TMPRSS2-ERG fusion, was associated with biochemical recurrence after radical prostatectomy. Association of specific gene fusions harboring higher genomic alterations with p53 mutations suggests that p53 mutations might drive more aggressive rearrangements of TMPRSS2-ERG fusion in prostate cancer.

Acknowledgements: The authors thank Ms. Kiyomi Fujita for her technical assistance regarding immunostaining. This work was not performed by any financial support.

\section{References}

[1] TOMLINS SA, RHODES DR, PERNER S, DHANASEKARAN SM, MEHRA R et al. Recurrent fusion of TMPRSS2 and ETS transcription factor genes in prostate cancer. Science 2005;310:644-648. http://dx.doi.org/10.1126/science. 1117679

[2] WANG J, CAI Y, REN C, ITTMANN M. Expression of variant TMPRSS2/ERG fusion messenger RNAs is associated with aggressive prostate cancer. Cancer Res 2006;66:8347-8451. http://dx.doi.org/10.1158/0008-5472.CAN-06-1966

[3] RUBIO-BRIONES J, FERNANDEZ-SERRA A, CALATRAVA A, GARCIA-CASADO Z, RUBIO L et al. Clinical implications of TMPRSS2-ERG gene fusion expression in patients with prostate cancer treated with radical prostatectomy. J Urol 2010;183:2054-2061. http://dx.doi.org/10.1016/j. juro.2009.12.096

[4] MAGI-GALLUZZI C, TSUSUKI T, ELSON P, SIMMERMAN $\mathrm{K}$, LAFARGUE $\mathrm{C}$ et al. TMPRSS2-ERG gene fusion prevalence and class are significantly different in prostate cancer of Caucasian, African-American and Japanese patients. Prostate 2011;71:489-497. http://dx.doi.org/10.1002/pros.21265

[5] SOLLER MJ, ISAKSSON M, ELFVING P, SOLLER W, LUNDGREN R et al. Confirmation of the high frequency of the TMPRSS2/ERG fusion gene in prostate cancer. Genes Chromosomes Cancer 2006;45:717-719. http://dx.doi.org/10.1002/ gcc.20329

[6] MOSQUERA JM, MEHRA R, REGAN MM, PERNER S, GENEGA EM et al. Prevalence of TMPRSS2-ERG fusion prostate cancer among men undergoing prostate biopsy in the United States. Clin Cancer Res 2009;15:4706-4711. $\underline{\text { http:// }}$ dx.doi.org/10.1158/1078-0432.CCR-08-2927

[8] SUHJH,PARKJW,LEEC,MOONKC.ERGImmunohistochemistry and Clinicopathologic Characteristics in Korean Prostate Adenocarcinoma Patients. Korean J Pathol 2012;46:423-428. http://dx.doi.org/10.4132/KoreanJPathol.2012.46.5.423

[9] LEE K, CHAE JY, KWAK C, KU JH, MOON KC. TMPRSS2ERG gene fusion and clinicopathologic characteristics of Korean prostate cancer patients. Urology 2010;76:1268 e7-13.

[10] ATTARD G, CLARK J, AMBROISINE L, FISHER G, KOVACS $G$ et al. Duplication of the fusion of TMPRSS2 to ERG sequences identifies fatal human prostate cancer. Oncogene 2008;27:253-263. http://dx.doi.org/10.1038/sj.onc.1210640

[11] BARRY M, PERNER S, DEMICHELIS F, RUBIN MA. TMPRSS2-ERG fusion heterogeneity in multifocal prostate cancer: clinical and biologic implications. Urology 2007;70:630633. http://dx.doi.org/10.1016/j.urology.2007.08.032

[12] GOPALAN A, LEVERSHA MA, SATAGOPAN JM, ZHOU Q, AL-AHMADIE HA et al. TMPRSS2-ERG gene fusion is not associated with outcome in patients treated by prostatectomy. Cancer Res 2009;69:1400-1406. http://dx.doi. org/10.1158/0008-5472.CAN-08-2467

[13] MUIR CS, NECTOUX J, STASZEWSKI J. The epidemiology of prostatic cancer. Geographical distribution and time-trends. Acta Oncol 1991;30:133-140. http://dx.doi. org/10.3109/02841869109092336 
[14] EPSTEIN JI, ALLSBROOK WC, JR., AMIN MB, EGEVAD LL, COMMITTEE IG. The 2005 International Society of Urological Pathology (ISUP) Consensus Conference on Gleason Grading of Prostatic Carcinoma. The American journal of surgical pathology 2005;29:1228-1242. http:// dx.doi.org/10.1097/01.pas.0000173646.99337.b1

[15] BUBENDORF L, NOCITO A, MOCH H, SAUTER G. Tissue microarray (TMA) technology: miniaturized pathology archives for high-throughput in situ studies. The Journal of pathology 2001;195:72-79. http://dx.doi.org/10.1002/path.893

[16] FALZARANO SM, ZHOU M, CARVER P, TSUZUKI T, SIMMERMAN K et al. ERG gene rearrangement status in prostate cancer detected by immunohistochemistry. Virchows Arch 2011;459:441-447. http://dx.doi.org/10.1007/s00428-011$1128-4$

[17] SUN QP, LI LY, CHEN Z, PANG J, YANG WJ et al. Detection of TMPRSS2-ETS fusions by a multiprobe fluorescence in situ hybridization assay for the early diagnosis of prostate cancer: a pilot study. J Mol Diagn 2010;12:718-724. http://dx.doi. org/10.2353/jmoldx.2010.100002

[18] MIYAGI Y, SASAKI T, FUJINAMI K, SANO J, SENGA Y et al. ETS family-associated gene fusions in Japanese prostate cancer: analysis of 194 radical prostatectomy samples. Mod Pathol 2010;23:1492-1498. http://dx.doi.org/10.1038/ modpathol.2010.149

[19] HERMANS KG, VAN MARION R, VAN DEKKEN H, JENSTER G, VAN WEERDEN WM et al. TMPRSS2:ERG fusion by translocation or interstitial deletion is highly relevant in androgen-dependent prostate cancer, but is bypassed in latestage androgen receptor-negative prostate cancer. Cancer Res 2006;66:10658-10663. http://dx.doi.org/10.1158/0008-5472. CAN-06-1871

[20] TOMLINS SA, BJARTELL A, CHINNAIYAN AM, JENSTER G, NAM RK et al. ETS gene fusions in prostate cancer: from discovery to daily clinical practice. Eur Urol 2009;56:275-286. http://dx.doi.org/10.1016/j.eururo.2009.04.036

[21] KOVACS G. Molecular cytogenetics of renal cell tumors. Advances in cancer research 1993;62:89-124. http://dx.doi. org $/ 10.1016 /$ S0065-230X(08)60316-4

[22] MARKERT EK, MIZUNO H, VAZQUEZ A, LEVINE AJ. Molecular classification of prostate cancer using curated expression signatures. Proceedings of the National Academy of Sciences of the United States of America 2011;108:2127621281. http://dx.doi.org/10.1073/pnas.1117029108

[23] BARWICK BG, ABRAMOVITZ M, KODANI M, MORENO CS, NAM R et al. Prostate cancer genes associated with TMPRSS2-ERG gene fusion and prognostic of biochemical recurrence in multiple cohorts. British journal of cancer 2010;102:570-576. http://dx.doi.org/10.1038/sj.bjc.6605519

[24] WEINMANN S, VAN DEN EEDEN SK, HAQUE R, CHEN C, RICHERT-BOE $\mathrm{K}$ et al. Immunohistochemical Expression of ERG in the Molecular Epidemiology of Fatal Prostate Cancer Study. Prostate 2013.

[25] KOLAR Z, BURDOVA A, Jamaspishvili T, Bouchal J, Kucerova $R$ et al. Relation of ETS transcription factor family member ERG, androgen receptor and topoisomerase 2beta expression to TMPRSS2-ERG fusion status in prostate can- cer. Neoplasma, 2014;61:9-16. http://dx.doi.org/10.4149/ neo 2014004

[26] MINNER S, GARTNER M, FREUDENTHALER F, BAUER $M$, KLUTH M et al. Marked heterogeneity of ERG expression in large primary prostate cancers. Mod Pathol 2013;26:106116. http://dx.doi.org/10.1038/modpathol.2012.130

[27] CARVER BS, TRAN J, GOPALAN A, CHEN Z, SHAIKH S et al. Aberrant ERG expression cooperates with loss of PTEN to promote cancer progression in the prostate. Nat Genet 2009;41:619-624. http://dx.doi.org/10.1038/ng.370

[28] KROHN A, DIEDLER T, BURKHARDT L, MAYER PS, DE SILVA C et al. Genomic deletion of PTEN is associated with tumor progression and early PSA recurrence in ERG fusion-positive and fusion-negative prostate cancer. Am J Pathol;181:401-412. http://dx.doi.org/10.1016/j. ajpath.2012.04.026

[29] HAN B, MEHRA R, LONIGRO RJ, WANG L, SULEMAN K et al. Fluorescence in situ hybridization study shows association of PTEN deletion with ERG rearrangement during prostate cancer progression. Mod Pathol 2009;22:1083-1093. http:// dx.doi.org/10.1038/modpathol.2009.69

[30] HE WW, SCIAVOLINO PJ, WING J, AUGUSTUS M, HUDSON P et al. A novel human prostate-specific, androgenregulated homeobox gene (NKX3.1) that maps to $8 \mathrm{p} 21$, a region frequently deleted in prostate cancer. Genomics 1997;43:69-77. http://dx.doi.org/10.1006/geno.1997.4715

[31] LEI Q, JIAO J, XIN L, CHANG CJ, WANG S et al. NKX3.1 stabilizes p53, inhibits AKT activation, and blocks prostate cancer initiation caused by PTEN loss. Cancer Cell 2006;9:367-378. http://dx.doi.org/10.1016/j.ccr.2006.03.031

[32] LEINONEN KA, SARAMAKI OR, FURUSATO B, KIMURA T, TAKAHASHI $\mathrm{H}$ et al. Loss of PTEN is associated with aggressive behavior in ERG-positive prostate cancer. Cancer Epidemiol Biomarkers Prev, 2013;22:2333-2344. http://dx.doi. org/10.1158/1055-9965.EPI-13-0333-T

[33] MATSUYAMA H, PAN Y, MAHDY EA, MALMSTROM PU, HEDRUM A et al. p53Deletion as a Genetic Maker in Urothelial Tumor by Fluorescence in situ Hydridization. Cancer Res 1994; 54: 6057-6060.

[34] SCHLOMM T, IWERS L, KIRSTEIN P, JESSEN B, KOLLERMANN J et al. Clinical significance of p53 alterations in surgically treated prostate cancers. Mod Pathol 2008;21:13711378. http://dx.doi.org/10.1038/modpathol.2008.104

[35] TAYLOR BS, SCHULTZ N, HIERONYMUS H, GOPALAN $\mathrm{A}, \mathrm{XIAO} \mathrm{Y}$ et al. Integrative genomic profiling of human prostate cancer. Cancer Cell 2010;18:11-22. http://dx.doi. org/10.1016/j.ccr.2010.05.026

[36] KARIM S, ALI A. Correlation of p53 over-expression and alteration in $\mathrm{p} 53$ gene detected by polymerase chain reactionsingle conformation polymorphism in adenocarcinoma of gastric cancer patients from India. World J Gastroenterol 2009; 15 1381-1387. http://dx.doi.org/10.3748/wjg.15.1381

[37] AGELL L, HERNANDEZ S, DE MUGA S, LORENTE JA, JUANPERE $N$ et al. KLF6 and TP53 mutations are a rare event in prostate cancer: distinguishing between Taq polymerase artifacts and true mutations. Mod Pathol 2008;21:1470-1478. http://dx.doi.org/10.1038/modpathol.2008.145 
[38] BASTUS NC, BOYD LK, MAO X, STANKIEWICZ E, KUDAHETTI SC et al. Androgen-induced TMPRSS2:ERG fusion in nonmalignant prostate epithelial cells. Cancer Res;70:9544-9548. http://dx.doi.org/10.1158/0008-5472. CAN-10-1638

[39] CHIU YT, LIU J, TANG K, WONG YC, KHANNA KK et al. Inactivation of ATM/ATR DNA damage checkpoint promotes androgen induced chromosomal instability in prostate epithelial cells. PLoS One 2012;7:e51108. http://dx.doi.org/10.1371/ journal.pone.0051108
[40] JIANG A, YU C, ZHANG P, CHEN W, LIU W et al. p53 overexpression represses androgen-mediated induction of NKX3.1 in a prostate cancer cell line. Exp Mol Med 2006;38:625-633. http://dx.doi.org/10.1038/emm.2006.74

[41] ZONG Y, XIN L, GOLDSTEIN AS, LAWSON DA, TEITELL MA et al. ETS family transcription factors collaborate with alternative signaling pathways to induce carcinoma from adult murine prostate cells. Proc Natl Acad Sci USA, 2009;106:12465-12470. http://dx.doi.org/10.1073/ pnas.0905931106 